\title{
MED23 in endocrinotherapy for breast cancer
}

\author{
BENRUI LIN ${ }^{1}$, LAN ZHANG ${ }^{2}$, DINUO LI ${ }^{1}$ and HONGZHI SUN ${ }^{1}$ \\ Departments of ${ }^{1}$ General Surgery and ${ }^{2}$ Thoracic Surgery, The First Affiliated Hospital \\ of Jinzhou Medical University, Jinzhou, Liaoning 121000, P.R. China
}

Received July 29, 2016; Accepted February 21, 2017

DOI: $10.3892 / \mathrm{ol} .2017 .6036$

\begin{abstract}
We investigated the role of the transcriptional mediator subunit 23 (MED23) in everolimus drug resistance, invasion and metastasis during breast cancer treatment and its molecular mechanism. We also evaluated the endocrinotherapy and prevention method for breast cancer. Breast cancer cell strains were established that can continuously express MED23, as well as inducible MED23-shRNA expression plasmids. The inductive agent, doxycycline (Dox), was added to the water for long-term silencing of MED23 in intratumoral cells. We conducted experiments on the role of MED23 in the regulation of invasion and metastasis of breast cancer using cell culture, western blotting, MTT proliferation experiment, fluorescent quantitative PCR and chromatin immunoprecipitation (ChIP). The silencing of MED23 significantly inhibited cellular growth and proliferation as well as soft agar cloning. Silencing of MED23 strengthened the sensitivity of the everolimus-resistant breast cancer cell strains BT474 and MCF-7/ADM cells to everolimus medication. The silencing of MED23, in combination with everolimus, inhibits the cell cycle progress of breast cancer cells. ChIP indicated that the mutual regulation of HER2 and MED23 also participates in the formation of the everolimus drug resistance mechanism. Therefore, MED23 plays an important role in everolimus drug resistance, invasion, and metastasis of breast cancer. As a potential molecular therapeutic target of breast cancer, MED23 overcomes drug resistance in clinical endocrinotherapy and controls the distal relapse and metastasis in breast cancer by the targeted silencing of MED23.
\end{abstract}

\section{Introduction}

Breast cancer is one of the most common malignant tumors and can severely threaten the health and life of females (1).

Correspondence to: Dr Hongzhi Sun, Department of General Surgery, The First Affiliated Hospital of Jinzhou Medical University, 2 Renmin Street, Jinzhou, Liaoning 121000, P.R. China

E-mail: sunhongzhi160720@163.com

Key words: breast cancer, MED23, everolimus, invasion, metastasis
In recent years, the incidence of breast cancer has been increasing rapidly. Breast cancer has become the most lethal malignant tumor in females around the world $(2,3)$. With the estrogen receptor (ER) as the target, the pure antiestrogenic endocrinotherapy drug of everolimus plays an important role in clinical treatment of breast cancer. However, the consequent drug resistance considerably decreases its therapeutic effects (4). Distal invasion and metastasis is the leading cause of death of breast cancer patients (5). Endocrinotherapy drug resistance and invasion and metastasis have become two major challenges in the clinical treatment of breast cancer (6). As a critical coactivator of ER, the transcriptional mediator subunit 23 (MED23) plays a critical role in the ER-dependent genetic expression and estrogen-dependent breast cancer growth; it also participates in the formation of drug resistance of tamoxifen, another endocrinotherapy drug. It is closely associated with the poor prognosis of breast cancer patients $(7,8)$.

MED23 is the original binding target of ER and it bonds to ER through two LXXLL motifs on the $\mathrm{N}$ end. A bridge forms between ER and RNA pol II participating in the regulation of transcriptional activities of ER-dependent genes (9). As a critical ER coactivator, MED23 is essential in the expression of the ER-dependent target genes and growth of the estrogen-dependent breast cancer cells (10).

Everolimus is mainly used for the treatment of refractory and metastatic breast cancer; it has a strong affinity with ER. It can effectively inhibit ER transcriptional activity, degrade the ER protein, and downregulate ER levels (11). Unfortunately, drug resistance can occur in many patients during everolimus treatment (12). The drug resistance of everolimus may be associated with multiple signaling pathways (EGFR, HER2, and ErbB3) of the growth factors, NF- $\kappa \mathrm{B}$ signaling pathway, Wnt/ $\beta$-catenin signaling pathway, non-ER-dependent autophagocytosis and microRNA. However, the mechanism of the drug resistance of everolimus remains unclear $(13,14)$.

Based on the establishment of silent MED23 breast cancer cell strains, this study investigated the mechanism of MED23 in regulating drug resistance of everolimus in the treatment of breast cancer and the mechanism of MED23 in regulating the invasion and metastasis of breast cancer. We also assessed the role of MED23 as a molecular therapy target with tissue specificity, to overcome the drug resistance of MED23 in endocrinotherapy for breast cancer in order to prevent and control the distant relapse and metastasis of breast cancer by the targeted silencing of MED23. 


\section{Materials and methods}

Cell culture. BT474 and MCF-7/ADM human breast cancer cell strains and human embryonic kidney cells 293T were purchased from American Type Culture Collection (Manassas, VA, USA). Breast cancer cells were transfected with the EFl-luc plasmid. The monoclonal cell strains (MCF-7/ADM-luc and BT474-luc) that stably expressed the firefly luciferase were screened with G418. Cells were cultured in the Dulbecco's modified Eagle's medium (DMEM) (Sigma, St. Louis, MO, USA) containing 10\% fetal bovine serum (GE Healthcare Life Sciences HyClone Laboratories, Logan, UT, USA) and penicillin/streptomycin double antibodies and $5 \% \mathrm{CO}_{2}$ at $37^{\circ} \mathrm{C}$. The screening drug pwomycin $(1 \mu \mathrm{g} / \mathrm{ml})$ (Invitrogen Life Technologies, Carlsbad, CA, USA) was added to maintain the genetic stability of positive colonies when the established inducible stable cell strains were cultured.

Establishment of the pLKO-Tet-On-MED23/GFP shRNA plasmid. The pLKO-Tet-On carrier vector was transformed into competent $E$. coli cells, applied to an LB agar plate (Sigma, Santa Clara, CA, USA) containing Amp, and allowed to stand at $37^{\circ} \mathrm{C}$. A total of $100 \mu$ l of competent cells (TOP10) were placed in an ice bath. A total of $4 \mu 1$ of pLKO-Tet-On was added. The cells were gently well-mixed with a pipette. The mixture was placed in an ice bath for $30 \mathrm{~min}\left(42^{\circ} \mathrm{C}, 90 \mathrm{sec}\right)$ and then placed in an ice bath for $5 \mathrm{~min}$. A total of $500 \mu \mathrm{l}$ of LB culture medium (Thermo Fisher Scientific, Waltham, MA, USA) was added and shaken at $37^{\circ} \mathrm{C}(300 \mathrm{x} \mathrm{g})$ for $30 \mathrm{~min}$. A total of $100 \mu \mathrm{l}$ of mixture was applied to the LB/Amp plate. It was placed in a bacteriological incubator at $37^{\circ} \mathrm{C}$ overnight. Monoclones were placed in the LB/Amp culture medium and vibrated $(300 \mathrm{x} \mathrm{g})$ at $37^{\circ} \mathrm{C}$ overnight. The plasmid DNA was extracted with the reagent kit. Enzyme digestion was performed to verify the carrier. Tet-on shRNA was used to sequence the primers (GGACGGAGTATCTACCTATATCTGTTCAGA). The established pLKO-Tet-On shRNA plasmid was entrusted to GENEWIZ for verification of sequencing (15).

Packaging lentiviral vector system. The 293T cells were seeded to a $10 \mathrm{~cm}$ culture dish and $20 \mu \mathrm{g}$ pLKO-Tet-On MED23 (or GFP) shRNA plasmid DNA, packaging plasmid (lentivirus coat plasmid) psPAX2, $10 \mu \mathrm{g}$, envelope plasmid (lentivirus membrane protein plasmid) pMD2.G, $6 \mu \mathrm{g}$ and water was added to make the volume $0.45 \mathrm{ml}$. A total of $50 \mu \mathrm{g}$ of $2.5 \mathrm{M} \mathrm{CaCl}_{2}$ was added and $0.5 \mathrm{ml}$ of 2 XHBS was added, it was incubated for $5 \mathrm{~min}$ at room temperature. The calcium phosphate-DNA sediment was added to the culture dish. Cells were cultured overnight at $37^{\circ} \mathrm{C}$ in an environment containing $5 \% \mathrm{CO}_{2}$. The collected supernatant of all cells was centrifuged at $1,500 \mathrm{x}$ g for $10 \mathrm{~min}$ and filtered with a $0.45-\mu \mathrm{m}$ filter membrane to remove the sediment. It was centrifuged in a $40 \mathrm{ml}$ ultra-centrifuge tube (Beckman Coulter, Hamburg, Germany) for $2 \mathrm{~h}$ at $8,000 \mathrm{xg}$ at $4^{\circ} \mathrm{C}$. A small volume of DMEM (without serum and antibiotic) was dissolved to re-suspend the virus (concentrated $\sim 6-8$-fold). Polybrene (final concentration $8 \mu \mathrm{g} / \mathrm{ml}$ ) (Thermo Fisher Scientific) was added. The solution was well mixed, packaged separately and stored at $-80^{\circ} \mathrm{C}$. The selected stable cell strains were subject to phenotypic detection.
Western blotting. Cells were digested with a pancreatic enzyme and collected in an EP tube. The cells were decomposed on ice for protein extraction after the addition of appropriate amount of RIPA buffer. The total protein concentration was detected with the Bradford method. The lysis solution containing 50 ugd and $5 \mathrm{X}$ protein loading buffer were mixed as per 4:1 and boiled for protein denaturation. It was transferred to a membrane and blocked for 1-2 $\mathrm{h}$ at room temperature after the addition of protein and electrophoresis. The membrane was immersed in the primary antibody diluted with TBST containing 5\% BSA (Abcam, Cambridge, UK) overnight. It was washed with TBST, immersed in the HRP-marked secondary antibody (fluorescein isothiocyanate-conjugated donkey anti-rabbit; dilution, 1:200; cat. no. 711-475-152) diluted with TBST $(1: 5,000)$ containing 5\% skim milk powder (Santa Cruz Biotechnology, Inc., Dallas, TX, USA) and incubated at room temperature. It was washed with TBST and developed with the ECL substrate (Thermo Fisher Scientific). It was developed in an X-ray developing machine for photographic fixing (PROTEC, Hamburg, Germany).

MTT cell proliferation experiment. After breast cancer cells were subjected to appropriate treatment, the single-cell suspension was inoculated into the 96-well microplate and regularly cultured for 4 days in the presence or absence of $20 \mu \mathrm{l}$ $5 \mathrm{mg} / \mathrm{ml}$ doxycycline (Dox). MTT (Sigma) was added to each well. The culture was terminated after $4 \mathrm{~h}$ and the supernatant was carefully pipetted and discarded. A total of $100 \mu 1 \mathrm{DMSO}$ was added to each well and horizontally shaken for $10 \mathrm{~min}$ for complete dissolution of the crystals. The OD value of each well was determined with the microplate reader (synergy II; BioTek, Winooski, VT, USA) at a wavelength of $490 \mathrm{~nm}$. A cell growth curve was plotted with time as the independent variable and the OD being the dependent variable after the OD value of the blank control well was deducted.

Crystal violet staining. The colony formation ability of BT474 and MCF-7/ADM cells was detected. A total of $5 \times 10^{3}$ cells were seeded in each well on a 12-well microplate. The cells were incubated overnight at $37^{\circ} \mathrm{C}$ for adherence. Different concentrations of drug were added to the experimental groups, respectively. DMSO was added to the control group. Three parallel wells were arranged in each group. The solution was changed twice each week and the culture medium was discarded after 10 days. The cells were washed twice with PBS, fixed for 5 min after addition of appropriate amount of methyl alcohol, and washed twice with PBS again. The water was completely pipetted, air dried, covered with a crystal violet solution, stained for $10 \mathrm{~min}$, rinsed off with tap water, washed with double distilled water, and observed under cx23 microscope (Olympus, Tokyo, Japan) for calculation of number of colonies.

RNA extraction, reverse transcription, and fluorescent quantitative PCR. The total RNA in purified cells was extracted in accordance with the instructions for the Qiagen RNA extraction kit (Qiagen, Hilden, Germany). The total RNA served as the template. The oligo (dT) 20 primer and SuperScript ${ }^{\mathrm{TM}}$ III reverse transcriptase (Invitrogen, Carlsbad, CA, USA) were used to synthesize the first chain cDNA. PCR reaction cycle 


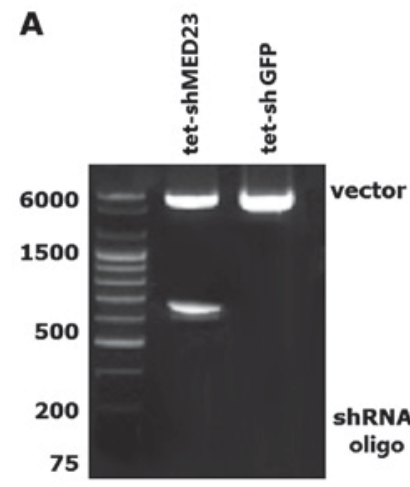

C
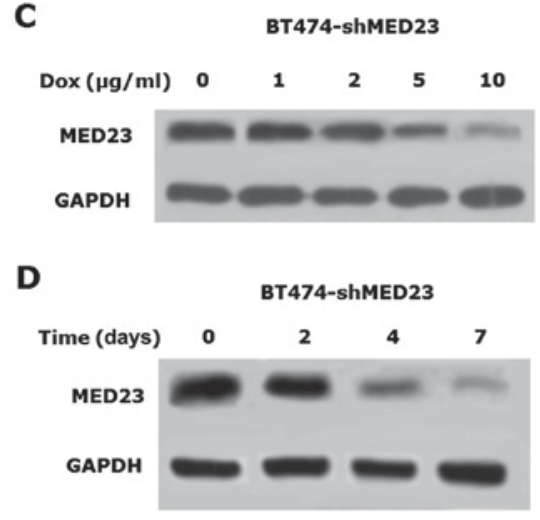

B
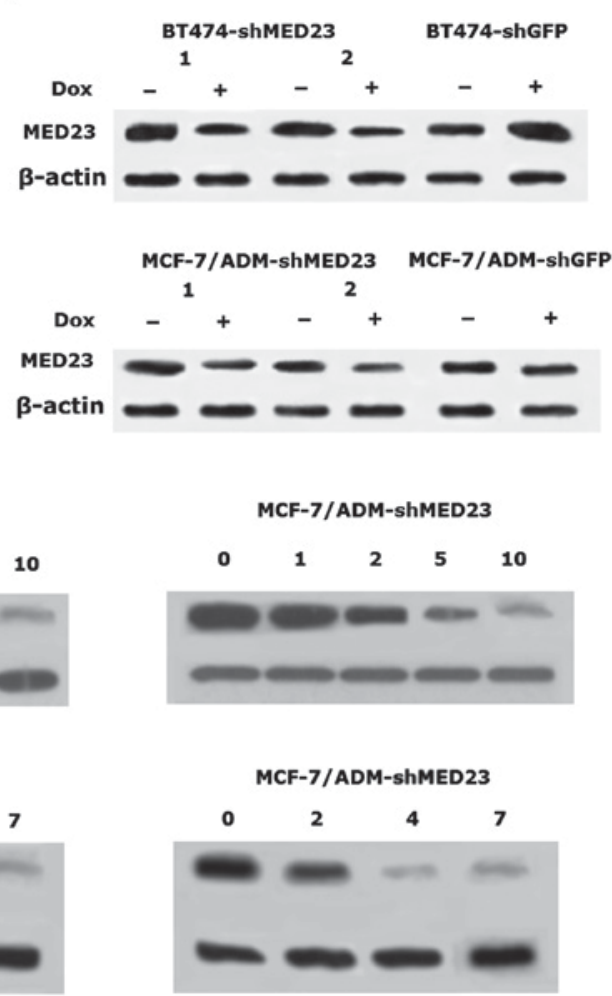

Figure 1. Screening of the inducible MED23 silent breast cancer cell strains. (A) Xhol single restriction enzyme digestion. (B) Expression of MED23 in inducible breast cancer cell strains following Dox induction treatment. (C) Inducible breast cancer cell strains: Expression of MED23 at different points in time after Dox induction. (D) Expression of MED23 after the inducible breast cancer cell strains were induced with Dox at different doses.

conditions: $1 \mathrm{x}: 50^{\circ} \mathrm{C} 2 \mathrm{~min}, 1 \mathrm{x}: 95^{\circ} \mathrm{C} 10 \mathrm{~min}, 42 \mathrm{x}: 95^{\circ} \mathrm{C} 12 \mathrm{sec}$; $58^{\circ} \mathrm{C} 40 \mathrm{sec} ; 72^{\circ} \mathrm{C} 45 \mathrm{sec}, 1 \mathrm{x}$ (separated): $95^{\circ} \mathrm{C} 15 \mathrm{sec} ; 60^{\circ} \mathrm{C}$ $30 \mathrm{sec} ; 95^{\circ} \mathrm{C} 15 \mathrm{sec}$. The $2-\Delta \mathrm{Acr}$ method was used to compute the relative mRNA expression of various standardized genes. Respective GAPDH expression levels served as the internal reference (16).

Chromatin immunoprecipitation (ChIP) experiment. The cells were washed twice with pre-cooled PBS, removed, centrifuged, incubated on ice after addition of lysis buffer, and diluted. The supernatant was collected after the cells were crushed using ultrasound. A total of $100 \mu 1+5 \mu \mathrm{l}$ of $5 \mathrm{M} \mathrm{NaCl}$ was used for input control. The supernatant was subject to immunoprecipitation. It was rotated for $2 \mathrm{~h}$ at $4^{\circ} \mathrm{C}$ after addition of salmon sperm DNA $2 \mu \mathrm{g}+$ pre-immune serum $20 \mu \mathrm{l}+$ protein A sepharose beads. A total of $25 \mu \mathrm{l}$ of supernatant and appropriate antibody (ER and MED23; Abcam, Cambridge, UK) were rotated overnight at $4^{\circ} \mathrm{C}$. A total of $30 \mu \mathrm{l}$ of protein A sepharose beads were rotated at $4^{\circ} \mathrm{C}$ for $4-6 \mathrm{~h}$. The solution was centrifuged at 1,200 $\mathrm{x} g$ for $2 \mathrm{~min}$ and the supernatant was discarded. After elution, the DNA was collected, purified with the DNA purification kit (Qiagen, Berlin, Germany), stored at $-20^{\circ} \mathrm{C}$ for later use, or directly used for real-time PCR. The TEEl (pS2) promoter primers used in the ChIP experiment are as follows: Forward, 5-TACGAAACACTCCTGCAGTGAG-3'; reverse, 5-GATCGTTAGATCACATTAGCC-3'.

Statistical analysis. All data were expressed as mean \pm standard deviation. Two-tailed Student's t-tests were used for the comparison of data between the two groups. The Dunn's post hoc t-test of one-way analysis of variance (one-way ANOVA) was used for the pairwise comparison of differences among multiple groups. Inspection level $\alpha=0.05, \mathrm{P}<0.05$ and $\mathrm{P}<0.01$.

\section{Results}

Establishment of the shMED23/shGFP plasmid and screening of the inducible MED23 silent breast cancer cell strains. The pLKO-Tet-On shMED23/shGFP vector plasmid was successfully established. In addition to the empty carrier band, there were two shRNA oligo-bands at 200 bp and below 200 bp (Fig. 1A). Results of the induction experiments at different points in time indicated that the effects of silencing MED23 in inducible cell strains were satisfactory after they were incubated with Dox for 4 days (Fig. 1B). The results of the induction experiments at different doses of Dox indicated that $5 \mu \mathrm{g} / \mathrm{ml}$ Dox was able to perfectly induce silencing of MED23 (Fig. 1C). In consideration of the toxicity associated with a high dose of Dox as well as observation of cell morphology, an inductive dose of $10 \mu \mathrm{g} / \mathrm{ml}$ Dox and 7-day incubation were used in subsequent experiments regarding breast cancer cells.

Effect of silent MED23 on periodical growth of breast cancer cells. Based on the distribution of the cell division cycles in inducible breast cancer cells in the presence or absence of Dox induction, we discovered that the number of cells that entered the S stage decreased significantly after the silencing of MED23 in BT474 and MCF-7/ADM inducible cells, which is downregulated by Dox $(\mathrm{P}<0.05)$ (Fig. 2). These results 
A

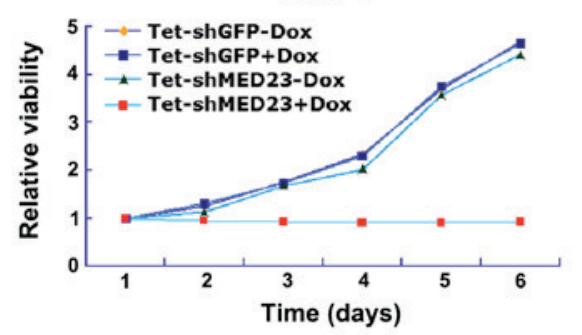

C

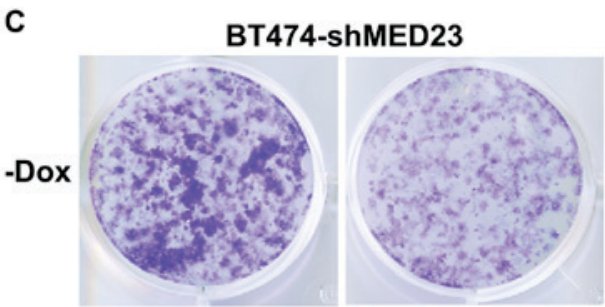

D

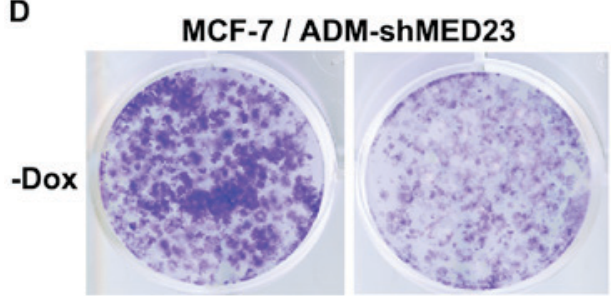

B

MCF-7 / ADM

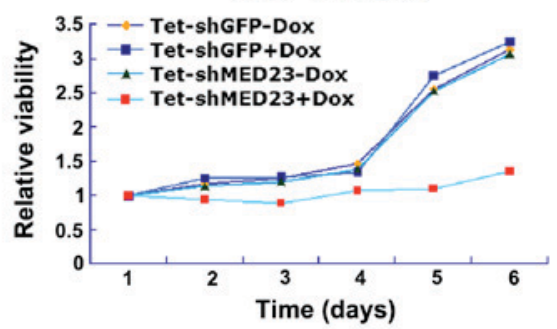

+ Dox
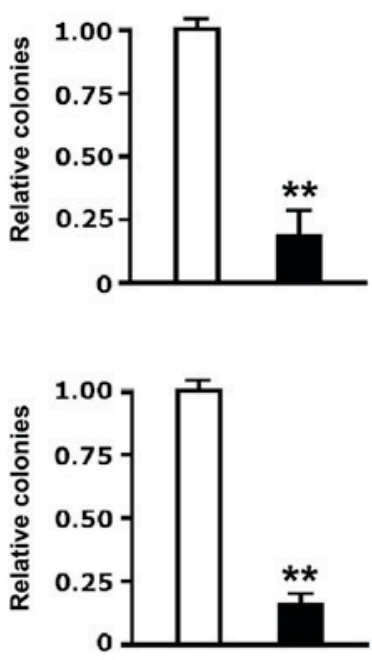

Figure 2. Result of division of the breast cancer cells after the silent MED23 was induced by Dox. (A) On the left are the BT474 cells not induced by Dox; on the right are the BT474 cells induced by Dox and the growth and proliferation were significant inhibited. (B) Bar graph of percentages of cells, the proportion of the Dox-induced cells in the $\mathrm{S}$ stage decreased significantly ("* $\mathrm{P}<0.01)$. ( $\mathrm{C}$ and $\mathrm{D})$ The growth and proliferation of the MCF-7/ADM cells induced by Dox were significantly inhibited; the proportion of Dox-induced cells in the $\mathrm{S}$ stage decreased significantly $\left({ }^{* *} \mathrm{P}<0.01\right)$.

A

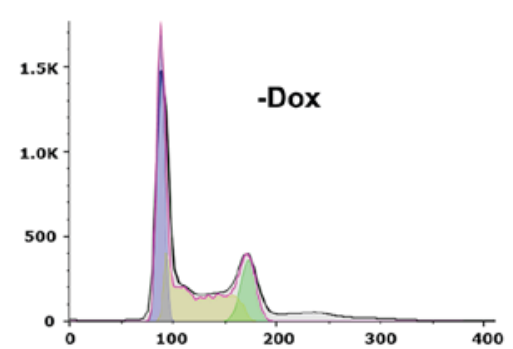

C

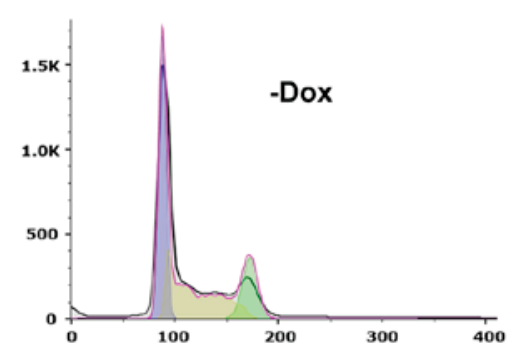

BT474-shMED23

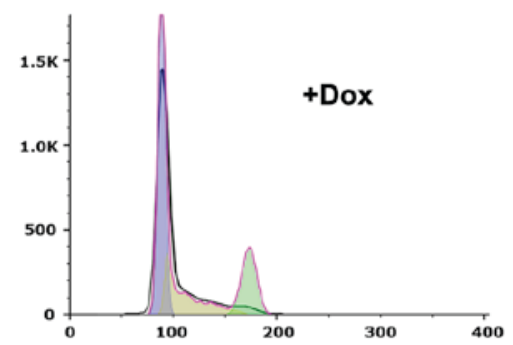

MCF-7IADM-shMED23

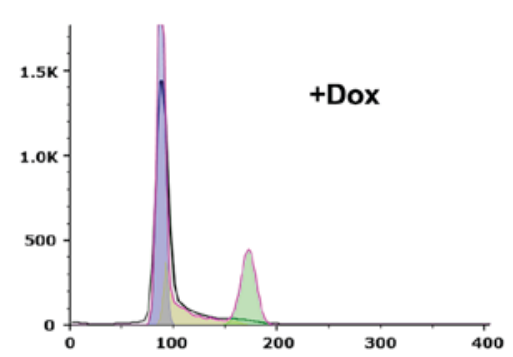

B

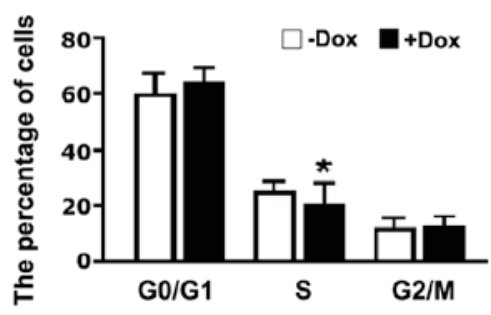

D

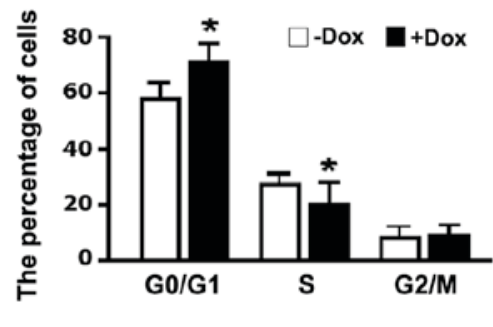

Figure 3. Effect of silent MED23 on growth of breast cancer cells and colony formation. (A) MTT cell proliferation experiment for growth trend of the Dox-induced BT474 cells. (B) Growth trend of MCF-7/ADM. (C) On the left is the comparison of crystal violet staining between the BT474 cells before Dox induction and those after Dox induction; on the right is the quantitative analysis for the number of colonies. (D) Analysis of number of colonies in the MCF-7/ADM cells ( $(\mathrm{P}<0.05)$.

indicate that MED23 plays an essential role in cell division cycles of breast cancer cells. The effect of MED23 silencing on the cell cycles may be one of the mechanisms of inhibition of growth in breast cancer cells. 
A

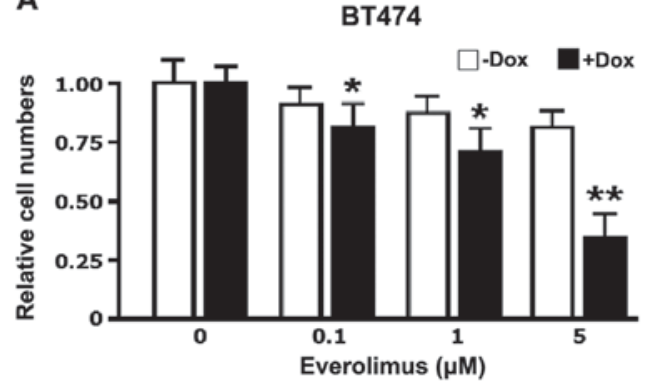

B

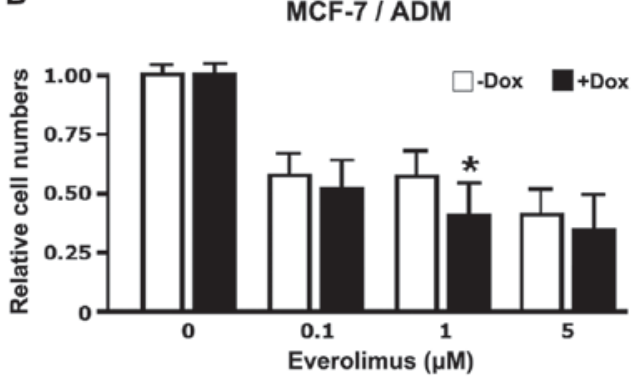

C

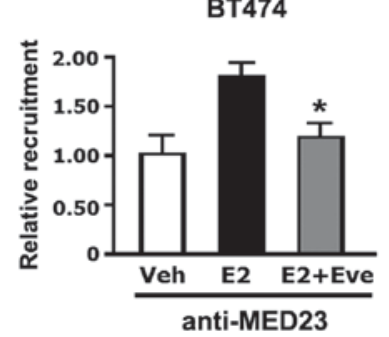

MCF-7 / ADM

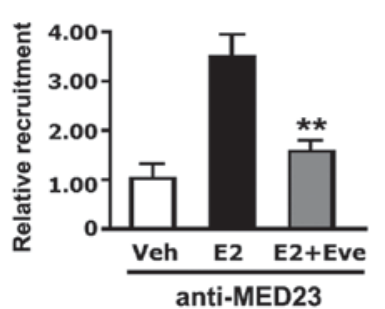

E

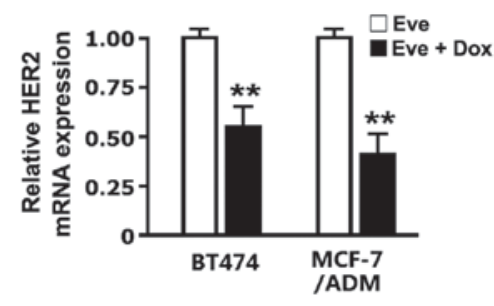

Figure 4. Correlation between silencing of everolimus and everolimus efficacy. (A and B) Silencing of MED23 strengthened the sensitivity of BT474 and MCF-7/ADM cells to everolimus. (C and D) Everolimus significantly inhibited the MCF-7/ADM cells and the activity of the BT474 cells after silencing of MED23. (E) Silencing MED23 in combination with everolimus drug treatment significantly inhibited the expression of the HER2 gene in the two types of cell lines $\left(\right.$ ( $\left.\mathrm{P}<0.05 ;{ }^{* *} \mathrm{P}<0.01\right)$.

Effects of silent MED23 on growth of the breast cancer cells and colony formation. The MTT cell proliferation experiment indicated that the growth of the Dox-induced Tet-shMED23 cells (BT474 and MCF-7/ADM) slowed down from the second day (Fig. 3A and B). In addition, the colony formation ability of breast cancer cells following Dox induction and MED23 silencing declined significantly $(\mathrm{P}<0.01 ;$ Fig. $3 \mathrm{C}$ and $\mathrm{D})$.

Silencing MED23 strengthens the sensitivity of everolimus and correlation with the HER2 pathway. BT474 cells were subjected to Dox-induced silencing at different concentrations. Silencing MED23 significantly decreased the number of breast cancer cells when everolimus was administered at concentrations of $0.1,1$, and $5 \mu \mathrm{M}(\mathrm{P}<0.05)$. Everolimus, at a concentration of $5 \mu \mathrm{M}$, and Dox induced silencing of MED23 achieved the optimal result ( $\mathrm{P}<0.01$; Fig. 4A). However, everolimus, at a concentration of $1 \mu \mathrm{M}$, and Dox induced silencing also achieved a significant effect. The CHIP experiment indicated that silencing MED23 led to a promotion in the role of everolimus by inhibiting the expression of the ER target gene (Fig. 4C and D). The ER target gene was significantly inhibited by everolimus in the MCF-7/ADM cells $(\mathrm{P}<0.01$; Fig. 4D). The real-time PCR results show that silencing of MED23 plays a role in the downregulation of HER2 expression under everolimus treatment (Fig. 4E).

\section{Discussion}

MED23 is the original binding target of ER and a critical ER coactivator. MED23 is essential in the expression of ER-dependent reporter genes, endogenous downstream target genes and growth of the estrogen-dependent breast cancer cells (17). Multiple cell strains, that can induce silent expression of MED23, are successfully screened by using the let-on carrier for the establishment of Tet (or Dox)-induced MED23 shRNA expression plasmid. The established inducible cell strains are used to verify the effects of MED23 knockdown on the growth of multiple types of breast cancer cell strains and ensure the reliability of the newly-established inducible cell strains (18). The expression of MED23 was significantly inhibited after these inducible breast cancer cells are treated with Dox. The growth of cells treated with Dox was found to decline significantly (19). We have also found that MED23 knockdown significantly arrests the mitosis cycle of the breast cancer cells (the number of cells that enter the $\mathrm{S}$ stage decrease) (20). The regulatory effect of MED23 on cell cycle may be one of the major mechanisms that regulate its participation in the growth of breast cancer cells.

The drug resistance that arises from the long-term use of everolimus frequently occurs in the treatment of patients with breast cancer. This has become a big challenge in the clinical treatment of breast cancer (21). Sufficient scientific evidence is provided to reveal the role of MED23 in everolimus drug sensitivity. This experiment has shown that silencing MED23 strengthens the sensitivity of the BT474 and MCF-7/ADM cells of everolimus-resistant breast cancer cell strains to everolimus medication and subsequently, its administration inhibits the progress of the breast cancer cell cycle and the expression of the endogenous target genes (22).

The present study indicates that the mutual regulation between HER2 and MED23 plays a critical role in the formation of drug resistance of everolimus in human breast cancer cells (23). Effects on ER may be an important molecular mechanism of MED23 in the participation in inducing drug resistance to everolimus (24). The MED23 and HER2 genes are located on the same human chromosome and are both amplified. MED23 is overexpressed in $\sim 40-60 \%$ of human breast cancer. Latest study has shown that the high MED23 expression levels are highly associated with poor prognosis 
of patients with breast cancer who receive endocrinotherapy. MED23 participates in formation of drug resistance of everolimus through mutual regulation with HER2 (25). The present study demonstrates that MED23 participates in the drug resistance of everolimus in endocrinotherapy, and explains that MED23 plays an extensive role in the regulation of the resistance of different types of endocrinotherapy drugs in breast cancer, and suggests that MED23 can function as a potential therapeutic target (sole or combined) to overcome the drug resistance of endocrinotherapy (26).

In conclusion, the present study reveals the critical role of MED23 in the drug resistance of endocrinotherapy everolimus and preliminarily explains its possible molecular mechanisms (27). Silencing MED23 promotes the role of everolimus treatment in the inhibition of the expression of the ER target gene. The mutual regulation between HER2 and MED23 also participates in the drug resistance of everolimus (28). In conclusion, as a promising potential tissue-specific molecular therapeutic target, MED23 overcomes drug resistance in clinical endocrinotherapy and prevents and controls the distal relapse and metastasis of breast cancer by the targeted silencing of MED23.

\section{References}

1. Zhu W, Harvey S, Macura KJ, Euhus DM and Artemov D Invasive breast cancer preferably and predominantly occurs at the interface between fibroglandular and adipose tissue. Clin Breast Cancer 17: e11-e18, 2017.

2. Halpern MT, Spain P, Holden DJ, Stewart A, McNamara EJ, Gay G, Das IP and Clauser S: Improving quality of cancer care at community hospitals: Impact of the National Cancer Institute Community Cancer Centers Program pilot. J Oncol Pract 9: e298-e304, 2013.

3. Krzysiek J, Wiatr J, Milewicz T, Wyroba J, KrzyczkowskaSendrakowska M, Galicka-Latała D, Rajtar-Ciosek A, KacalskaJanssen O, Zmaczyński A, Stochmal E, et al: The incidence of neoplasm in women using contraceptives. Przegl Lek 67: 519-522, 2010 (In Polish).

4. Hoffmann J and Sommer A: Steroid hormone receptors as targets for the therapy of breast and prostate cancer - recent advances, mechanisms of resistance, and new approaches. J Steroid Biochem Mol Biol 93: 191-200, 2005.

5. Ottewell PD, O'Donnell L and Holen I: Molecular alterations that drive breast cancer metastasis to bone. Bonekey Rep 4: 643, 2015

6. Khajah MA, Almohri I, Mathew PM and Luqmani YA Extracellular alkaline $\mathrm{pH}$ leads to increased metastatic potential of estrogen receptor silenced endocrine resistant breast cancer cells. PLoS One 8: e76327, 2013.

7. Buteau-Lozano H, Velasco G, Cristofari M, Balaguer P and Perrot-Applanat M: Xenoestrogens modulate vascular endothelial growth factor secretion in breast cancer cells through an estrogen receptor-dependent mechanism. J Endocrinol 196: 399-412, 2008

8. Filigheddu N, Cutrupi S, Porporato PE, Riboni F, Baldanzi G, Chianale F, Fortina E, Piantanida P, De Bortoli M, Vacca G, et al: Diacylglycerol kinase is required for HGF-induced invasiveness and anchorage-independent growth of MDA-MB-231 breast cancer cells. Anticancer Res 27 (3B): 1489-1492, 2007.

9. Ahn HJ, Jung SJ, Kim TH, Oh MK and Yoon HK: Differences in clinical outcomes between luminal A and B type breast cancers according to the St. Gallen Consensus 2013. J Breast Cancer 18: 149-159, 2015.

10. Armstrong MJ, Stang MT, Liu Y, Yan J, Pizzoferrato E and Yim JH: IRF-1 inhibits NF- $\kappa$ B activity, suppresses TRAF2 and cIAP1 and induces breast cancer cell specific growth inhibition. Cancer Biol Ther 16: 1029-1041, 2015.
11. Weaver DL, Ashikaga T, Krag DN, Skelly JM, Anderson SJ, Harlow SP, Julian TB, Mamounas EP and Wolmark N: Effect of occult metastases on survival in node-negative breast cancer. N Engl J Med 364: 412-421, 2011.

12. Caruso A, Iacopetta D, Puoci F, Cappello AR, Saturnino C and Sinicropi MS: Carbazole derivatives: A promising scenario for breast cancer treatment. Mini Rev Med Chem 16: 630-643, 2016.

13. Marsigliante S, Vetrugno C and Muscella A: CCL20 induces migration and proliferation on breast epithelial cells. J Cell Physiol 228: 1873-1883, 2013.

14. Huang FI, Chen YL, Chang CN, Yuan RH and Jeng YM: Hepatocyte growth factor activates Wnt pathway by transcriptional activation of LEF1 to facilitate tumor invasion. Carcinogenesis 33: 1142-1148, 2012.

15. Jaure O, Alonso EN, Braico DA, Nieto A, Orozco M, Morelli C, Ferro AM, Barutta E, Vincent E, Martínez D, et al: BRCA1 polymorphism in breast cancer patients from Argentina. Oncol Lett 9: 845-850, 2015.

16. Saikawa Y, Sugiura T, Toriumi F, Kubota T, Suganuma K, Isshiki S, Otani Y, Kumai K and Kitajima M: Cyclooxygenase-2 gene induction causes CDDP resistance in colon cancer cell line, HCT-15. Anticancer Res 24: 2723-2728, 2004.

17. Morrison MM, Williams MM, Vaught DB, Hicks D, Lim J, McKernan C, Aurisicchio L, Ciliberto G, Simion C, Sweeney C, et al: Decreased LRIG1 in fulvestrant-treated luminal breast cancer cells permits ErbB3 upregulation and increased growth. Oncogene 35: 1206, 2016.

18. Wang ZQ, Wang J, Ling WH, Zhang XG and Shi Q: Effects of CD40 ligation combined with chemotherapy drugs on human breast cancer cell lines. J Int Med Res 41: 1495-1504, 2013.

19. Wang L, Zhang X, Chan JY, Shan L, Cui G, Cui Q, Wang Y, Li J, Chen $\mathrm{H}$, Zhang Q, et al: A novel danshensu derivative prevents cardiac dysfunction and improves the chemotherapeutic efficacy of doxorubicin in breast cancer cells. J Cell Biochem 117: 94-105, 2016.

20. Capasso A: Vinorelbine in cancer therapy. Curr Drug Targets 13: 1065-1071, 2012

21. Fiorillo M, Verre AF, Iliut M, Peiris-Pagés M, Ozsvari B, Gandara R, Cappello AR, Sotgia F, Vijayaraghavan A and Lisanti MP: Graphene oxide selectively targets cancer stem cells, across multiple tumor types: Implications for non-toxic cancer treatment, via 'differentiation-based nano-therapy'. Oncotarget 6: 3553-3562, 2015

22. Li XY, Luo QF, Wei CK, Li DF, Li J and Fang L: miRNA-107 inhibits proliferation and migration by targeting CDK8 in breast cancer. Int J Clin Exp Med 7: 32-40, 2014.

23. Kaur M and Badhan RK: Phytoestrogens modulate breast cancer resistance protein expression and function at the blood-cerebrospinal fluid barrier. J Pharm Pharm Sci 18: 132-154, 2015.

24. Toyoda $Y$ and Ishikawa T: Pharmacogenomics of human ABC transporter ABCC11 (MRP8): Potential risk of breast cancer and chemotherapy failure. Anticancer Agents Med Chem 10: 617-624, 2010.

25. Chen M, He M, Song Y, Chen L, Xiao P, Wan X, Dai F and Shen P: The cytoprotective role of gemcitabine-induced autophagy associated with apoptosis inhibition in triple-negative MDA-MB-231 breast cancer cells. Int J Mol Med 34: 276-282, 2014.

26. Calaf GM, Zepeda AB, Castillo RL, Figueroa CA, Arias C, Figueroa E and Farías JG: Molecular aspects of breast cancer resistance to drugs (Review). Int J Oncol 47: 437-445, 2015.

27. Tan X, Marshall VD, Anderson RT, Donohoe J, Camacho F and Balkrishnan R: Adjuvant therapy use among Appalachian breast cancer survivors. Medicine (Baltimore) 94: e1071, 2015.

28. Khongkow P, Gomes AR, Gong C, Man EP, Tsang JW, Zhao F, Monteiro LJ, Coombes RC, Medema RH, Khoo US, et al: Paclitaxel targets FOXM1 to regulate KIF20A in mitotic catastrophe and breast cancer paclitaxel resistance. Oncogene 35: 990-1002, 2016. 